\title{
Identification and ranking of the risky organic contaminants in the source water of the Danjiangkou reservoir
}

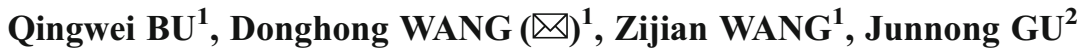 \\ 1 State Key Laboratory of Environmental Aquatic Chemistry, Research Center for Eco-Environmental Sciences, Chinese Academy of Sciences, \\ Beijing 100085, China \\ 2 Water Quality Monitoring Center, Beijing Waterworks Group Co. Ltd., Beijing 100081, China
}

(C) Higher Education Press and Springer-Verlag Berlin Heidelberg 2013

\begin{abstract}
The Danjiangkou reservoir was selected to provide the source water for the middle routes of the South to North Water Transfer Project, which has provoked many environmental concerns. To date, investigations of water contamination of the source water of the Danjiangkou reservoir with organic micro-pollutants have been limited. This study was conducted to identify and rank organic contaminants that pose risks in the Danjiangkou reservoir. To this end, the Chemical Hazard Evaluation and Management Strategies (CHEMS-1) approach was adapted to integrate the deconvolution technology of qualitative identifying contaminants for site-specific environmental matrices. The samples were screened for the presence of 1093 contaminants using deconvolution technologies and the hazard values of the identified contaminants were calculated using the adapted CHEMS- 1 approach according to their hazardous properties and occurrence in source water. The results showed that 46 contaminants from 1093 targets were present in Danjiangkou water, 23 of which appeared at frequencies higher than $50 \%$, and 15 of which were identified as priorities. Over half $(53 \%)$ of the highranked contaminants were polycyclic aromatic hydrocarbons (PAHs), with chrysene ranked highest on the list. Health risk assessment of the top-ranked PAHs was conducted and revealed that cancer risks of PAHs detected in the source water of Danjiangkou to different populations ranged from $10^{-7}$ to $10^{-6}$, indicating a low cancer risk to consumers. The results of this study indicated that the adapted CHEMS-1 approach was feasible for site-specific screening of organic contaminants to identify and rank potential priority pollutants.
\end{abstract}

Keywords identification and ranking, source water, deconvolution, risk assessment, Danjiangkou, South to

Received December 29, 2011; accepted March 3, 2013

E-mail: dhwang@rcees.ac.cn
North Water Transfer Project

\section{Introduction}

Ensuring the safety of source water remains a major focus because of the direct and indirect threats to human health from water contaminants [1-3], although the quality of drinking water has improved worldwide in the past 30-40 years [4]. Recently however, the use and release of a vast number of chemicals into the environment have made the situation worse, and brought great challenges to water management and drinking water processing [2,5].

Conventionally, the quality of source water was regulated according to the standards established by different countries and organizations [6-8] to ensure the quality of tap water. However, water managers have expressed uncertainty as to whether some remaining unregulated contaminants should be included in the regulations. The approaches applied to identify and prioritize unregulated contaminants were summarized in our previous review [9]. As an example, the United States Environmental Protection Agency (USEPA) publishes a Contaminant Candidate List (CCL) every five years under the authorization of the Safe Drinking Water Act [10]. The third CCL list was published in 2009 and included 104 chemicals or chemical groups and 12 microbiological contaminants that were not included in the current drinking water regulations. Conversely, about 82000 chemicals were listed in the USEPA Toxic Substances Control Act inventory [11], and 95\% of the most commonly used chemicals consist of organic substances. For site-specific source water, it is neither possible nor reasonable to conduct a full hazard assessment for all chemicals. Therefore, identification of the organic contaminants posing the highest human health and/or ecological risks in source water is of great importance. 
The Danjiangkou reservoir is located in central China and has a drainage area of $9.52 \times 10^{4} \mathrm{~km}^{2}$ [12]. This reservoir was selected as the water source for the middle routes of the South to North Water Transfer Scheme, which is a multi-decade infrastructure project to better utilize China's water resources. The scheme provides water to many districts along the routes, including Beijing. This water diversion scheme has provoked many environmental concerns $[13,14]$. However, investigations of water contamination of the source water of Danjiangkou by organic micro-pollutants have been limited to date. Therefore, it is of great importance to identify organic contaminants that pose risks in the Danjiangkou reservoir for further evaluation and management.

The purpose of this study was to identify and rank organic contaminants in the source water of Danjiangkou that pose risks. To accomplish, the Chemical Hazard Evaluation and Management Strategies (CHEMS-1) approach $[15,16]$ was adapted to integrate the deconvolution technology of qualitative identifying contaminants for site-specific environmental matrices. CHEMS-1 has been developed to provide a relative assessment of chemical risks to human health and the environment [16]. The method was selected because it is simple to use, sufficiently flexible to apply to other applications, and in line with our scenario analysis. The introduction of the identification method offered occurrence data for CHEMS1 , which used the release amount as an estimate of exposure for a particular contaminant. The adapted approach was validated and applied to identify and rank organic contaminants in the source water of Danjiangkou.
Although the main function of the Danjiangkou reservoir is to supply drinking water, ecological risk was included in the adapted approach considering the importance of ecological status to water safety and function. Finally, the health risk of the top-ranked contaminants was evaluated.

\section{Materials and methods}

\subsection{Chemicals and materials}

All solvents (methanol, acetone, dichloromethane (DCM), $n$-hexane) were of pesticide grade and supplied by Mallinckrodt Baker Inc. (USA). The ultra-pure water used in this study was generated by a Milli-Q system (Milli-Q Biocel, Millipore, USA). Solid phase extraction (SPE) was conducted using C18 cartridge (500 mg, $6 \mathrm{~mL}$ ) from Supeclo (USA) and Oasis hydrophilic-lipophilic balance (HLB) cartridge $(500 \mathrm{mg}, 6 \mathrm{~mL})$ from Waters (USA).

\subsection{Sample collection and pretreatment}

Based on the water functional types and the objectives of this study, the environs of the Danjiangkou Dam were selected as the study area. The contamination status of the study area may reflect the worst-case scenario, due to the relatively more intense human activities in this zone. Five national monitoring cross-sections were selected: Xiaotaipingyang (XTPY), Taizishan (TZS), Baqian (BQ), Caiwan

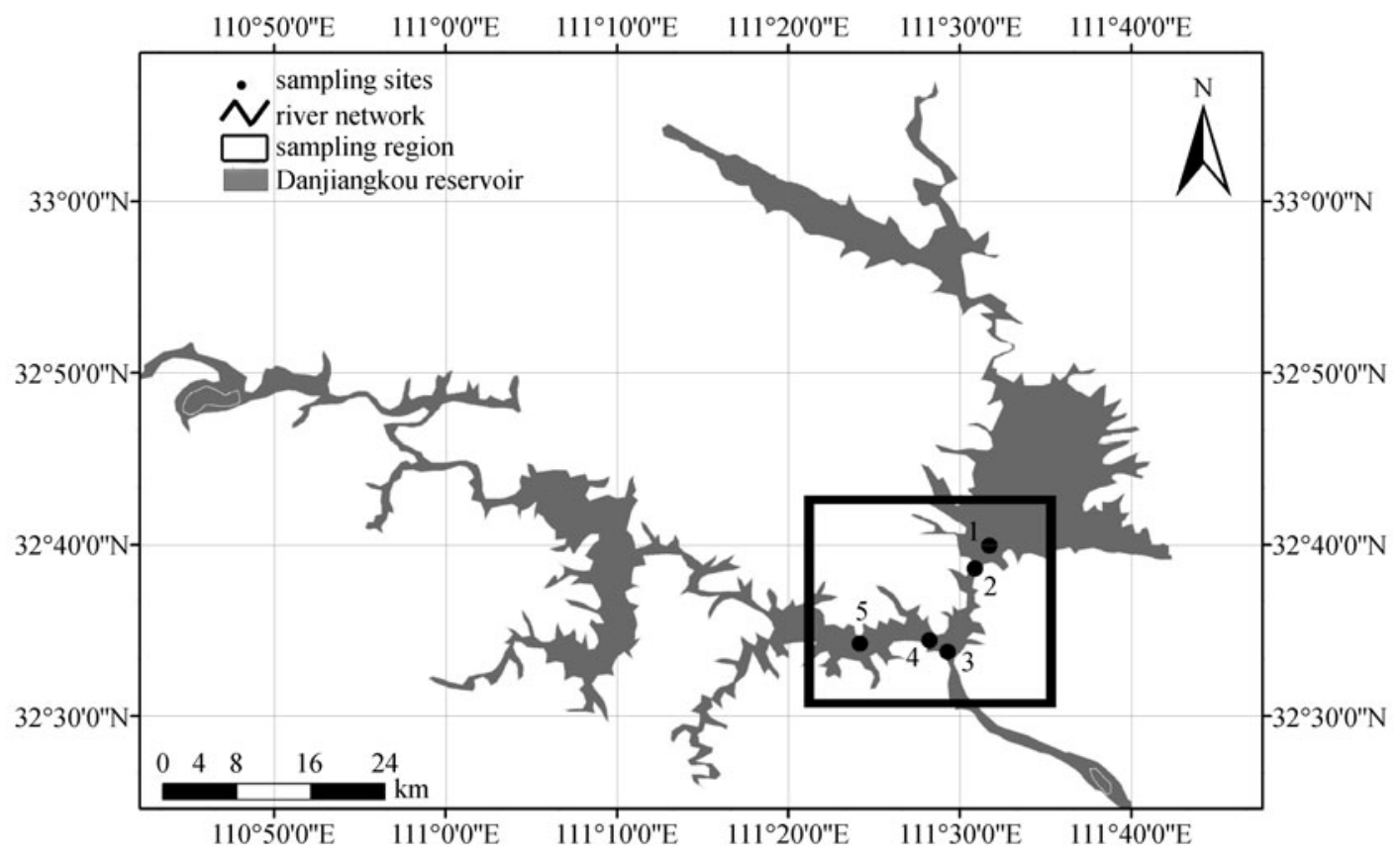

Fig. 1 Sampling sites of source water in Danjiangkou. Sampling sites: 1, XTPY; 2, TZS; 3, BQ; 4, CW; 5, LHK 
(CW) and Langhekou (LHK) (Fig. 1). Sections XTPY and TZS are located in the Danjiang reach. CW and LHK are located in the Hanjiang reach. At each section, $2 \mathrm{~L}$ of water was collected in May 2011. A total of five samples at different sites were collected in the study area. All samples were filtered using Millipore glass microfiber filters $(0.7$ $\mu \mathrm{m}, \Phi 142 \mathrm{~mm}$, Millipore, USA) and immediately preserved in amber glass bottles with $5 \%$ methanol at $4^{\circ} \mathrm{C}$. Phenanthrene-d10 was spiked into water samples prior to extraction as a surrogate standard during sample pretreatment. The samples were enriched by SPE with $\mathrm{C} 18$ coupled with HLB cartridges within $24 \mathrm{~h}$. The cartridges were eluted by $10 \mathrm{~mL}$ of DCM. The extracts were concentrated under a gentle stream of nitrogen and analyzed by gas chromatography-mass selective detector (GC-MSD).

\subsection{Instrumental analysis}

The samples were analyzed using an Agilent 6890 GC connected to Agilent MSD 5975 mass selective detector (Agilent Technologies, USA) equipped with a DB-5 capillary column $(30 \mathrm{~m} \times 0.25 \mathrm{~mm}$ i.d. $\times 0.25 \mu \mathrm{m}$ film thickness, J\&W Sci., USA). Highly pure helium (99.9999\%) was used as the carrier gas. In this study, two retention time locked (RTL) databases, Hazardous Contaminant Database (HCD) and Pesticide and Endocrine Disruptor Database, were used to screen the potential contaminants in the samples. For the HCD method, the constant pressure mode was used during the whole analysis process. The oven temperature was held at $40^{\circ} \mathrm{C}$ for $2 \mathrm{~min}$, raised to $300^{\circ} \mathrm{C}$ at $10^{\circ} \mathrm{C} \mathrm{min}^{-1}$ and held for $15 \mathrm{~min}$. The inlet and mass spectrometry (MS) transfer line temperatures were both set at $250^{\circ} \mathrm{C}$, and the ion source temperature was $230^{\circ} \mathrm{C} .1 \mu \mathrm{L}$ of the sample was injected in splitless mode. For the Pesticide and Endocrine Disruptor Database method, GC-MSD conditions were the same as for HCD method with the exception of the oven temperature, which was held at $70^{\circ} \mathrm{C}$ for $2 \mathrm{~min}$, raised to $150^{\circ} \mathrm{C}$ at $25^{\circ} \mathrm{C} \mathrm{min}{ }^{-1}$, raised to $200^{\circ} \mathrm{C}$ at $3^{\circ} \mathrm{C} \cdot \mathrm{min}^{-1}$, raised to $280^{\circ} \mathrm{C}$ at $8^{\circ} \mathrm{C} \mathrm{min}^{-1}$ and held for $15 \mathrm{~min}$. RTL, data acquisition and processing were performed by the Agilent MSD ChemStation Software (version E.0200.493, Agilent Technologies, USA).

Polycyclic aromatic hydrocarbons (PAHs) were determined using Agilent GC-MSD in the selected ion monitoring mode. A DB-5 capillary column $(30 \mathrm{~m} \times$ $0.25 \mathrm{~mm}$ i.d. $\times 0.25 \mu \mathrm{m}$ film thickness, J\&W Sci., USA) was equipped with helium as the carrier gas. The flow rate was maintained at $1 \mathrm{~mL} \cdot \mathrm{min}^{-1}$ during analysis. The injection temperature was set at $300^{\circ} \mathrm{C}$. The chromatographic column was held at $50^{\circ} \mathrm{C}$ for $2 \mathrm{~min}$, raised to $200^{\circ} \mathrm{C}$ at $20^{\circ} \mathrm{C} \mathrm{min}^{-1}$, held for $2 \mathrm{~min}$, raised to $290^{\circ} \mathrm{C}$ at $3^{\circ} \mathrm{C} \cdot \mathrm{min}^{-1}$ and held for $15 \mathrm{~min} .1 \mu \mathrm{L}$ of sample was injected in splitless mode. Quantification of PAHs was conducted based on comparison of peak area with PAH standard.

\subsection{Automatic screening and identification of chemicals}

The samples were analyzed by GC-MSD using the RTL method detailed above. The scan data were analyzed using Deconvolution Reporting Software (DRS) to identify the contaminants in samples. There are 1655 contaminants in the two above-mentioned databases, with 562 contaminants in both databases, or 1093 individual contaminants. The database covers a wide range of contaminants, including pesticides and their metabolites, endocrine disruptors, important polychlorinated biphenyls, PAHs, some dyes (e.g., sudan red), organophosphorus fire retardants, etc [17]. The identification of contaminants was based on three characteristic ions located at the correct retention time and with the correct relative ion intensity. DRS is a marriage of three different GC-MSD software packages: 1) the Agilent GC-MSD ChemStation, 2) the National Institute of Standards and Technology (NIST) Mass Spectral Search Program with NIST 08 MS library, and 3) the Automated Mass Spectral Deconvolution and Identification System (AMDIS) software, also from NIST. Retention index data were employed to identify the contaminants in samples. The deconvolution parameters in AMDIS were fixed as follows: adjacent peak subtraction: one; resolution: medium; sensitivity: high; shape requirements: medium. More details on DRS settings can be found in Agilent's application notes and literature elsewhere [18-20].

\subsection{Adapted CHEMS-1 method}

\subsubsection{Parameters and endpoints in the adapted CHEMS-1}

In this study, an adapted version of CHEMS-1 was used to rank contaminants in water samples. CHEMS-1 was developed to assess safer substitutes for hazardous chemicals listed in Toxics Release Inventory data and annual pesticide usage data. Different exposure routes to different receptors were considered in CHEMS-1, while not all of the endpoints were used in the adapted version considering the matrix studied. In particular, release amount for a particular contaminant was substituted by detection frequency to characterize exposure potential in the real environment. The detection frequency of a particular contaminant refers to the ratio of the number of sites where the positive DRS results were obtained in the qualitative screening to the total number of sites. Table 1 lists the parameters and endpoints used in the adapted CHEMS-1.

\subsubsection{Scoring method and algorithm}

The scoring algorithm for hazard value $(H V)$ was established as descried in the previous studies $[15,16]$. In brief, a total hazard value $\left(H V_{\mathrm{t}}\right)$ for a contaminant was 
Table 1 Parameters and endpoints used in the adapted algorithm

\begin{tabular}{lcc}
\hline parameter & type of toxicity/criteria & endpoint \\
\hline human health effects & acute & rodent oral LD50 \\
chronic & chronic & other specific effects, including cholinesterase inhibitor, developmental or reproductive toxin, \\
endocrine disruptor
\end{tabular}

Notes: LD50, medium lethal dose; BCF, bioaccumulation factor; LC50, medium lethal concentration; NOEL, no-observed effect level

calculated as the production of exposure and effect scores:

$$
H V_{\mathrm{t}}=\left(H V_{\mathrm{Env}}+H V_{\mathrm{Hum}}\right) \times H V_{\mathrm{Exp}},
$$

where $H V_{\mathrm{t}}, H V_{\mathrm{Env}}, H V_{\mathrm{Hum}}$, and $H V_{\text {Exp }}$ are hazard values for total hazard, environmental effects, human health effects, and exposure potentials, respectively.

$H V_{\text {Env }}$ was the sum of hazard values for acute aquatic toxicity $\left(H V_{\mathrm{FA}}\right)$ and the chronic aquatic toxicity $\left(H V_{\mathrm{FC}}\right)$ :

$$
H V_{\mathrm{Env}}=a H V_{\mathrm{FA}}+b H V_{\mathrm{FC}},
$$

where $a$ and $b$ are weighting factors.

$H V_{\text {Hum }}$ was the sum of hazard values for acute oral toxicity $\left(H V_{\mathrm{OR}}\right)$, carcinogenicity $\left(H V_{\mathrm{CAR}}\right)$ and other specific chronic effects $\left(H V_{\mathrm{NC}}\right)$ to humans:

$$
H V_{\mathrm{Hum}}=c H V_{\mathrm{OR}}+d H V_{\mathrm{CAR}}+e H V_{\mathrm{NC}},
$$

where $c, d$ and $e$ are weighting factors.

$H V_{\text {Exp }}$ was the sum of the hazard values for persistence $\left(H V_{\mathrm{HYD}}\right)$ and bioaccumulation $\left(H V_{\mathrm{BCF}}\right)$ :

$$
H V_{\mathrm{Exp}}=f H V_{\mathrm{HYD}}+g H V_{\mathrm{BCF}},
$$

where $f$ and $g$ are weighting factors.

For the adapted version, frequency-weighted hazard value $\left(w H V_{\mathrm{t}}\right)$ was calculated as follows:

$$
\begin{aligned}
w H V_{\mathrm{t}}= & \left(H V_{\mathrm{Env}}+H V_{\mathrm{Hum}}\right) \times H V_{\mathrm{Exp}} \\
& \times \text { Frequency, }
\end{aligned}
$$

All of the toxicity terms were equally weighted by assigning a hazard value to each, ranging on a scale from 0 to 5 . The hazard value for very high or low toxicities was assigned as 5 or 0 , respectively, according to the chosen cutoff values for the endpoints [16]. The scoring method was the same as that in CHEMS-1 except $w H V_{\mathrm{t}}$. Refer to Davis et al. [15] and Swanson et al. [16] for more details on scoring toxicity terms and the calculation of hazard values.

\subsubsection{Data selection}

\subsubsection{Human health effects}

Experimental data were preferred, and they were obtained from the USEPA ECOTOXicology (ECOTOX, Release 4.0, USA) database and/or the Pesticide Action Network (PAN, version 10.0, USA) database for 14 days acute rodent oral LD50. The most sensitive test result was selected if more than one experimental data point was available. The Toxicity Estimation Software Tools (TEST, version 4.0, USA) was used to estimate LD50 values if experimental data were unavailable. If toxicity data (either experimental or modeled data) were unavailable, $H V$ was set as 0 .

International Agency for Research on Cancer (IARC) ratings were used for carcinogenicity rankings. If neither the IARC nor the EPA had grouped the chemical according to its carcinogenicity, the $H V$ value was set as 0 . As for other specific effects, cholinesterase inhibition effects, developmental or reproductive effects, and endocrine disruption effects were considered. Experimental data for these specific effects were obtained from the PAN database.

\subsubsection{Environmental effects}

Experimental fish LC50 data were preferred and obtained from the ECOTOX database. TEST was used to estimate the 96-h fathead minnow toxicity data if experimental data were unavailable. As described in Swanson et al. [16], the LC50 data were selected in the following order of preference: 1) Pimephales promelas (fathead minnow) in a 96-h flow-through test; 2) 96-h flow-through LC50 data for other freshwater fish (excluding trout); 3) a static 96-h fathead minnow test; 4) a static 96-h test for other freshwater fish (excluding trout); and 5) the 96-h fathead minnow result estimated using TEST. 
As described in Swanson et al. [16], the fish NOEL data were estimated from fish LC50 and octanol-water partition coefficient $\left(K_{\text {ow }}\right)$.

\subsubsection{Persistence}

Hydrolysis half-life $\left(t_{1 / 2}\right)$ data were selected to characterize persistence of the contaminants. CHEMFATE (SRC Inc., USA) and BioDEG (SRC Inc., USA) databases were used to search for experimental hydrolysis half-life data. The most conservative value was selected if more than one experimental data were available. Persistent, Bioaccumulative, and Toxic (PBT) profiler data were selected in case of the absence of experimental data.

\subsubsection{Bioaccumulation}

Aquatic bioconcentration factor (BCF) data in CHEMFATE were retrieved as the source of experimental BCF data. The most conservative experimental value was selected if more than one data point for BCF was available. Estimation Program Interface Suite (EPISuite, version 4.0, USA) from USEPA was used to estimate BCF values if there were no experimental data.

\subsubsection{Detection frequency}

The detection frequency for one particular contaminant was calculated as the ratio of the number of samples detected to the total. The detection frequency was used as the weighting factor in the adapted CHEMS-1 approach.

\subsection{Quality assurance/quality control}

For qualitative analysis, good recoveries were desired for a broad range of contaminants with varying properties. To validate, the recoveries of contaminants with different $\lg K_{\text {ow }}$ were calculated. For 54 contaminants with $\lg K_{\text {ow }}$ from 1.44 to 6.75 , the recoveries were $60.2 \%-128.1 \%$. Therefore, this method can satisfy the need for preliminary qualitative screening for a broad range of contaminants with varying properties. For PAH quantification, the contaminant-free ultra-pure water was spiked with PAHs in six duplicates. The recoveries of PAHs were $80.5 \%$ $110.6 \%$, with relative standard deviations less than $15 \%$. The method detection limit was $0.01-0.06 \mu \mathrm{g} \cdot \mathrm{L}^{-1}$. Method blanks were run and no contaminants were found. The recoveries of the surrogate standard (phenanthrene-d10) were $77.1 \% \pm 8.6 \%$, with a range of $66.3 \%-89.0 \%$.

\subsection{Statistical analysis}

Statistical analyses, including the multiple linear regression analysis, Kolmogorov-Smirnov test, statistical significance test, and Pearson correlation test, were performed by using SPSS software package (version 13.0, SPSS Inc., Chicago, IL, USA). A critical $p$ value (statistical significance level) of 0.05 was used to determine goodness of fit.

\section{Results and discussion}

\subsection{Reliability of the adapted CHEMS-1 method}

For a good-ranking algorithm, each individual term should make an equivalent contribution to the final results [16]. Multiple linear regression analysis was run for $H V_{\mathrm{t}}$ versus $H V_{\text {Env }}, H V_{\text {Hum }}$, and $H V_{\text {Exp }}$, respectively. To test whether particular terms dominated $H V_{\mathrm{t}}$, the standardized regression coefficients were calculated. In statistics, the standardized regression coefficient is usually calculated to determine which independent variable has a greater effect on the dependent variable, reflecting the relative importance of each independent variable. The standardized regression coefficients of $H V_{\mathrm{Env}}, H V_{\mathrm{Hum}}$, and $H V_{\mathrm{Exp}}$ versus $H V_{\mathrm{t}}$ were $0.58,0.42$, and 0.39 , respectively, indicating that parameters in the algorithm possess equivalent weights.

Moreover, correlations between each individual parameter value were examined. The correlations were not significant $(p>0.05)$ for most of the test pair parameter values. The strong correlation between fish LC50 and fish NOEL $(r=0.999)$ occurred because fish NOEL was estimated from fish LC50 using quantitative structureactivity relationships. The above analysis showed that the adapted CHEMS-1 approach was proper for ranking the contaminants with potential risks in the source water of the Danjiangkou reservoir.

3.2 Identification and ranking of the potential risky contaminants

\subsubsection{Identification}

All samples were analyzed using DRS. The AMDIS match values were higher than $60 \%$, and the retention time differences between the expected and observed values were less than $10 \mathrm{~s}$. Moreover, the identification was reverse-matched with the NIST 08 library using the extracted spectrum. The results showed that 46 contaminants in 17 chemical classes were identified in water samples of the Danjiangkou reservoir (Table 2), 23 of which were detected at frequencies higher than $50 \%$. The following contaminants were detected in all the samples: acenaphthene, 2-methylnaphthalene, difenoxuron, benzophenone, naphthalene, terbutol, phenanthrene, fluoranthene, anthracene, biphenyl, o-phenylphenol, phenol, and fluorene. Additionally, the following contaminants were detected in almost all the samples: dibenzofuran, 9,10-anthraquinone, chrysene, pyrene, metribuzin, bromo- 
propylate, chlorflurecol-methyl ester, sec-butylbenzene, 3.2.2 Ranking results triclosan, and diphenylamine. All detected contaminants are listed in Table 2.

The results shown in Table 2 were derived by applying the

Table 2 Ranking results for contaminants from the adapted CHEMS-1 algorithm

\begin{tabular}{|c|c|c|c|c|c|}
\hline \multirow{2}{*}{ CAS No. ${ }^{\text {a) }}$} & \multirow{2}{*}{ contaminant } & \multirow{2}{*}{ chemical class } & \multirow{2}{*}{ frequency $/ \%$} & \multicolumn{2}{|c|}{ rank } \\
\hline & & & & weighted by frequency & not weighted by frequency \\
\hline $218-01-9$ & chrysene & $\mathrm{PAH}$ & 80 & $1(100)^{b)}$ & $2(96)$ \\
\hline $91-20-3$ & naphthalene & РAH & 100 & $2(99)$ & $6(76)$ \\
\hline $1918-11-2$ & terbutol & carbamate & 100 & $3(92)$ & $7(70)$ \\
\hline $85-01-8$ & phenanthrene & PAH & 100 & $4(91)$ & $8(70)$ \\
\hline $206-44-0$ & fluoranthene & PAH & 100 & $5(86)$ & $11(66)$ \\
\hline $120-12-7$ & anthracene & $\mathrm{PAH}$ & 100 & $6(85)$ & $12(65)$ \\
\hline $83-32-9$ & acenaphthene & PAH & 100 & $7(75)$ & $20(57)$ \\
\hline $92-52-4$ & biphenyl & biphenyl & 100 & $8(70)$ & $22(53)$ \\
\hline $90-43-7$ & $o$-phenylphenol & phenol & 100 & $9(67)$ & $23(51)$ \\
\hline $129-00-0$ & pyrene & PAH & 80 & $10(66)$ & $15(63)$ \\
\hline $132-64-9$ & dibenzofuran & furan & 80 & $11(62)$ & $18(59)$ \\
\hline $3380-34-5$ & triclosan & chlorinated phenol & 60 & $12(60)$ & $5(77)$ \\
\hline $108-95-2$ & phenol & phenol & 100 & $13(52)$ & $33(40)$ \\
\hline $18181-80-1$ & bromopropylate & benzilate & 60 & $14(50)$ & $16(63)$ \\
\hline $91-57-6$ & 2-methylnaphthalene & PAH & 100 & $15(48)$ & $35(37)$ \\
\hline $21087-64-9$ & metribuzin & triazine & 80 & $16(45)$ & $29(43)$ \\
\hline $56-55-3$ & benzo[a]anthracene & PAH & 40 & $17(43)$ & $3(82)$ \\
\hline $14214-32-5$ & difenoxuron & urea & 100 & $18(42)$ & $38(32)$ \\
\hline $119-61-9$ & benzophenone & ketone & 100 & $19(39)$ & $40(30)$ \\
\hline $84-65-1$ & 9,10 -anthraquinone & quinone & 80 & $20(38)$ & $36(37)$ \\
\hline $2536-31-4$ & chlorflurecol methyl ester & $\mathrm{PAH}$, ester & 60 & $21(34)$ & $28(43)$ \\
\hline $135-98-8$ & sec-butylbenzene & substitute benzene & 60 & $22(32)$ & $31(41)$ \\
\hline $122-39-4$ & diphenylamine & amine, biphenyl & 60 & $23(32)$ & $32(41)$ \\
\hline $2463-84-5$ & dicapthon & organophosphorus & 40 & $24(31)$ & $17(59)$ \\
\hline $52-85-7$ & famphur & organophosphorus & 40 & $25(30)$ & $19(58)$ \\
\hline $50-32-8$ & benzo[a]pyrene & $\mathrm{PAH}$ & 40 & $26(29)$ & $21(56)$ \\
\hline $86-73-7$ & fluorene & PAH & 100 & $27(28)$ & $41(21)$ \\
\hline $205-99-2$ & benzo[b]fluoranthene & PAH & 20 & $28(26)$ & $1(100)$ \\
\hline $119-90-4$ & $o$-dianisidine & biphenyl & 40 & $29(22)$ & $30(43)$ \\
\hline $101-05-3$ & anilazine & triazine & 20 & $30(21)$ & $4(79)$ \\
\hline $1420-06-0$ & trifenmorph & morpholine & 20 & $31(18)$ & $9(70)$ \\
\hline $2597-03-7$ & phenthoate & organophosphorus & 20 & $32(18)$ & $10(67)$ \\
\hline $207-08-9$ & benzo[k]fluoranthene & PAH & 20 & $33(17)$ & $13(64)$ \\
\hline $92-67-1$ & 4-aminobiphenyl & biphenyl & 20 & $34(17)$ & $14(63)$ \\
\hline $1912-24-9$ & atrazine & triazine & 20 & $35(13)$ & $24(51)$ \\
\hline $208-96-8$ & acenaphthylene & PAH & 20 & $36(13)$ & $25(48)$ \\
\hline $57-97-6$ & 7,12-dimethylbenz[a]anthracene & PAH & 20 & $37(12)$ & $26(45)$ \\
\hline $541-73-1$ & 1,3-dichlorobenzene & substitute benzene & 20 & $38(12)$ & $27(44)$ \\
\hline $105-67-9$ & 2,4-dimethylphenol & phenol & 20 & $39(10)$ & $34(38)$ \\
\hline $626-43-7$ & 3,5-dichloroaniline & amine & 20 & $40(9)$ & $37(34)$ \\
\hline
\end{tabular}


(Continued $)$

\begin{tabular}{|c|c|c|c|c|c|}
\hline \multirow{2}{*}{ CAS No. ${ }^{\text {a) }}$} & \multirow{2}{*}{ contaminant } & \multirow{2}{*}{ chemical class } & \multirow{2}{*}{ frequency $/ \%$} & \multicolumn{2}{|c|}{ rank } \\
\hline & & & & weighted by frequency & not weighted by frequency \\
\hline $26259-45-0$ & secbumeton & triazine & 20 & $41(8)$ & $39(31)$ \\
\hline $134-62-3$ & $N, N$-diethyl- $m$-toluamide & benzamide & 40 & $42(7)$ & $43(14)$ \\
\hline $58-08-2$ & caffeine & botanical & 40 & $43(6)$ & $46(11)$ \\
\hline $78-59-1$ & isophorone & ketone & 20 & $44(4)$ & $42(17)$ \\
\hline $78-40-0$ & triethyl phosphate & organophosphorus & 20 & $45(3)$ & $44(13)$ \\
\hline $98-86-2$ & acetophenone & ketone & 20 & $46(3)$ & $45(12)$ \\
\hline
\end{tabular}

Notes: a) CAS No, chemical abstract service registration number; b) Number in parentheses is the total hazard value for one particular chemical, normalized to a $0-100$ scale

adapted CHEMS-1 algorithm to the contaminants identified in water samples of the Danjiangkou reservoir. Both the $H V_{\mathrm{t}}$ and $w H V_{\mathrm{t}}$ values were calculated according to Eqs. (1)-(5) and normalized to a 0-100 scale.

A Kolmogorov-Smirnov test of the $H V_{\mathrm{t}}$ scores revealed a Gaussian distribution with a mean of 50.7 and a standard deviation of 21.5. The same distribution was found for $w H V_{\mathrm{t}}$ scores with a mean of 38.4 and a standard deviation of 28.6. These findings indicated that the adapted CHEMS1 algorithm performed well at differentiating contaminants according to their environmental exposure and harmfulness to human health and the environment [21].

The ranking of contaminants based on the frequencyweighted and unweighted results are presented in Table 2 . The top 15 ranked contaminants from the unweighted results were mainly from seven classes of chemicals: PAHs, triazine, chlorinated phenol, carbamate, mopholine, organophosphorus, and biphenyl. Nine of the top 15 ranked contaminants were PAHs.

However, the frequency weighted results were different from the unweighted results. This difference was because unweighted results were obtained according to the PBT properties, which are inherent chemical properties of contaminants. Chrysene, naphthalene, terbutol, phenanthrene, fluoranthene, anthracene, pyrene, and triclosan were ranked high among the top 15 contaminants from both the weighted and unweighted results due to their inherent hazardous properties and high detection frequencies. Moreover, benzo[a]anthracene, benzo[b]fluoranthene, anilazine, trifenmorph, phenothoate, benzo[k]fluoranthene, and 4-aminobiphenyl were ranked high in the unweighted results but low in the frequency-weighted results because of the low frequency of detection. Furthermore, acenaphthene, biphenyl, ophenylphenol, dibenzofuran, phenol, bromopropylate, and 2-methylnaphthalene were less toxic but ranked high when weighted by frequency because of the high frequency of detection in the source water.

The top-ranked chemicals should receive more attention in source water management and further studies. However, it should be noted that the ranking results do not reflect the actual estimates of hazards or risks. This approach offers a relative assessment of risk and identifies contaminants that show the greatest risks and should be of the most concern.

\subsubsection{Uncertainty of ranking results}

A good ranking method should not only identify contaminants that pose risks, but also should promote relative studies to reduce uncertainties associated with data gaps [22]. Uncertainty analysis associated with data gaps allows researchers to decide on future studies (e.g., toxicity tests, improvement of analytical methods, monitoring on a larger scale, etc.). A rough estimation was conducted for the uncertainty associated with data gaps. Briefly, for each endpoint, a value of 0 was assigned if experimental data were used to calculate the hazard scores. The uncertainty score was set at 3 if modeled data were employed and at 5 if neither experimental nor modeled data were available. The uncertainty value for each endpoint was summed to determine the total uncertainty value $\left(U N_{t}\right)$. Figure 2 shows the uncertainty scores versus hazard values of the identified contaminants. Contaminants possessing high hazard values (bottom right of Fig. 2) should be listed as

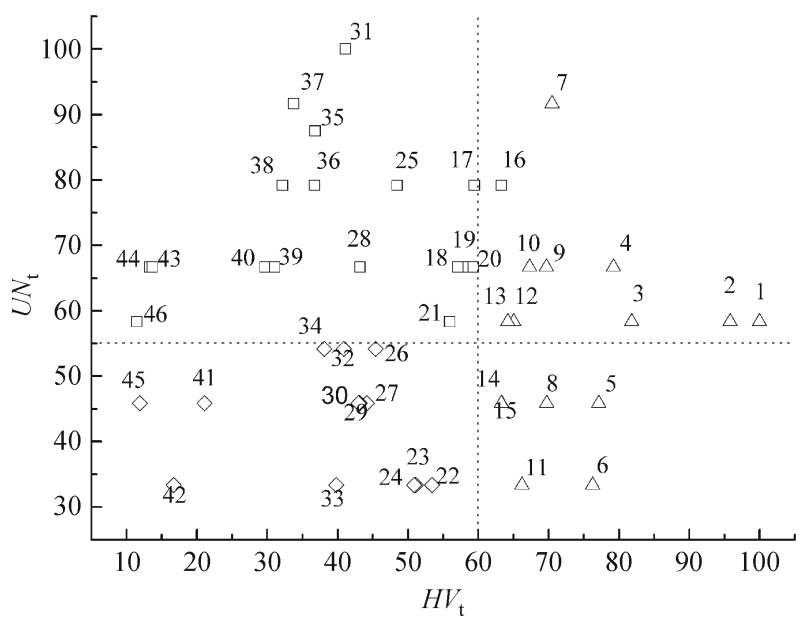

Fig. 2 Uncertainty scores versus hazard values of contaminants. Refer to Table 2 for compound number in the figure, which is the ranking order according to unweighted results 
priority pollutants of concern. Moreover, those contaminants that had higher uncertainty scores (top left of Fig. 2) should be focused on in future research to confirm whether these contaminants pose risks or not.

The total uncertainty was associated with data gaps of endpoints characterizing exposure potential (persistence and bioaccumulation), environmental effects (acute and chronic fish toxicities), and human health effects (acute rodent toxicity, carcinogenicity, and other specific effects). The contribution to uncertainty of different parameters for selected contaminants (with normalized uncertainty scores higher than 55) are diagramed in Fig. 3. The contribution was equal for the three parameters for most contaminants. There is a need to strengthen studies of both hazard assessment and exposure assessment in the future to fill data gaps.

\subsection{Priority pollutants}

The 15 top-ranked contaminants from frequency-weighted results should be placed under risk control measures for the Danjiangkou reservoir. Among the 15 priority pollutants, only PAHs were regulated by Chinese Standards for Drinking Water [6]. No standards for the remaining priority pollutants have been established to date. More than $50 \%$ of the 15 priority pollutants are regulated by the USEPA Drinking Water Advisory, however, the standards need to be revised for use in China because of the differing consumption habits between populations [23].

PAHs are of concern because of their potentially toxic, carcinogenic, and mutagenic effects on animals and humans [24]. They were usually related to sources such as vehicle exhaust, urban sewage, or chemical-, coke- and oil-shale industries [25]. To date, only a few studies have reported the PAH contamination in the Danjiangkou reservoir [26,27].

Phenols comprise a large group of organic contaminants in aquatic environments due to their high water solubility, strong reactivity, and poor biodegradation [28]. Three phenols were ranked high in this study: phenol, $O$ phenylphenol, and triclosan. Phenol is an important raw material in the production of pesticides, dyes, and paper. Exposure to phenol and its vapors may cause harm to the eyes, skin and respiratory tract [29]. o-phenylphenol is used as a fungicide, germicide, household disinfectant, and laboratory reagent. Triclosan is an antibacterial and antifungal agent used in many personal care products. Existing evidence has shown that triclosan acts as an endocrine disruptor in the environment [30,31]. Moreover, triclosan can combine with chlorine to form chloroform [32], which poses a risk of cancer.

Three pesticides, terbutol, dibenzofuran and bromopropylate, were ranked high in water from the Danjiangkou reservoir. Terbutol is used as an insecticide and an herbicide on turf grass. Reports have suggested that terbutol is cytotoxic, and the mitochondrial respiratory system and protein thiols were important targets of this pesticide [33]. Dibenzofuran, a heterocyclic organic compound, is used as an insecticide and in industrial bleaching and incineration by various industries. Accord-

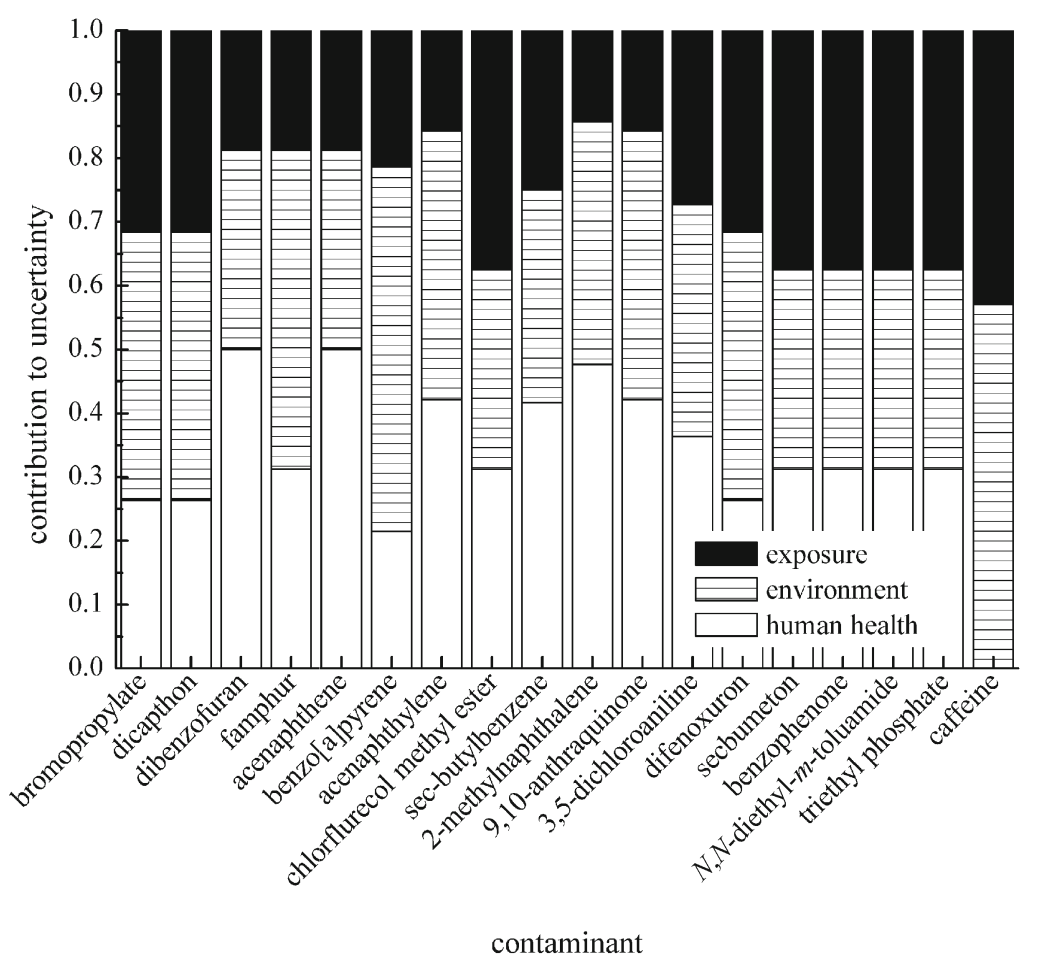

Fig. 3 Contribution to uncertainty of different parameters for selected contaminants 
ing to Mizukami [34], dibenzofuran is as toxic as dioxins. Bromopropylate is one of the most common acaricides used in agriculture.

Biphenyl is used extensively in medicines, dyes, and pesticides. According to the European Union (EU) classification, biphenyl is dangerous to the environment, and it is on the EU list of suspect of endocrine disruptors [35].

The Danjiangkou reservoir is subject to strict environmental management, so the identified contaminants did not enter from direct pollution by local sources. Possible routes of pollution include the migration and transport of contaminants from the upper reaches of Hanjiang and Danjiang Rivers. Shiyan, which is located in the upper reaches of the Hanjiang River, may be the main source of PAHs due to the heavy automobile industry in this region. Moreover, domestic sewage and industrial wastewater from the upper reaches of the Danjiang River may be a possible source of phenols [36]. Three pesticides (terbutol, dibenzofuran and bromopropylate) likely enter the system via agricultural non-point sources in the upper reaches of the Danjiangkou watershed [36,37]. Although there were trace amounts of pollution in the upper reaches of the Danjiangkou watershed, the water in the reservoir had good quality [38].

In conclusion, $53 \%$ of the top-ranked contaminants were PAHs, with chrysene ranked first. Of the priority pollutants, only PAHs were regulated according to their total amount or the amount of benzo[a]pyrene $(\mathrm{BaP})$ in China. The pollution may be attributed to exogenetic sources. Efforts are needed to derive environmental standards for these contaminants to adequately assess their risks. Additionally, data concerning the concentration, fate and behavior of contaminants in the Danjiangkou reservoir that pose risks are urgently needed. More detailed assessments should be conducted on these top-ranked contaminants to confirm whether they pose risks to human health and the environment.

\subsection{Health risk assessment of PAHs}

According to the results and discussion above, PAHs were highly ranked when compared with other pollutants. Quantitative analysis was conducted to further confirm the risk of PAHs to humans. Concentrations of detected PAHs are listed in Table 3. PAH concentrations ranged from 7.36 to $179.9 \mathrm{ng} \cdot \mathrm{L}^{-1}$. Due to the similar mode of action of PAHs, the toxicity of PAH mixtures was calculated as the toxicity equivalent quantity based on $\mathrm{BaP}\left(T E Q_{\mathrm{BaP}}\right)$, which was the sum of all individual PAH concentrations multiplied by their specific toxicity equivalence factors to $\mathrm{BaP}$ [39]. The $T E Q_{\mathrm{BaP}}$ was $4.05 \mathrm{ng}$ $\cdot \mathrm{L}^{-1}$ on average, which is lower than the drinking water standard of $10 \mathrm{ng} \cdot \mathrm{L}^{-1}$ for $\mathrm{BaP}$.

The incremental life cancer risk (ILCR) for PAHs was calculated according to the USEPA guidelines [40]:

$$
I L C R=\frac{T E Q_{\mathrm{BaP}} \times D R \times C S F \times E F \times E D}{B W \times A T \times 10^{6}},
$$

where $D R$ is the daily intake of water $\left(\mathrm{L} \cdot \mathrm{d}^{-1}\right), C S F$ is the cancer slope factor for $\mathrm{BaP}\left(\mathrm{kg} \cdot \mathrm{d} \cdot \mathrm{mg}^{-1}\right), E F$ is the exposure frequency per year (d), $E D$ is the exposure duration (years), $B W$ is the bodyweight of the exposed person $(\mathrm{kg})$, and $A T$ is life expectancy of the exposed person (d).

A consumption habit model for people in Beijing was employed in this study, since water from the Danjiangkou reservoir will be transferred to Beijing in the near future. The cancer risk of PAHs to people in young $(<20$ years old), middle-aged (20-64 years old) and elderly (>64 years old) age groups, was calculated according to different consumption habits using Eq. (6). Different

Table 3 Quantitative results of PAHs $\left(n=5 ; \mathrm{ng} \cdot \mathrm{L}^{-1}\right)$

\begin{tabular}{lccc}
\hline contaminant & TR & range & average \\
\hline naphthalene & Y & $14.5-124.8$ & 84.1 \\
acenaphthene & Y & - & - \\
phenanthrene & Y & $121.4-316.7$ & 179.9 \\
anthracene & Y & ND-15.84 & 7.36 \\
fluoranthene & Y & $16.8-20.3$ & 19.5 \\
pyrene & Y & $7.48-60.1$ & 22.2 \\
chrysene & Y & ND-118.5 & 52.7 \\
acenaphthylene & & - & - \\
fluorene & & $13.1-33.8$ & 20.4 \\
benzo[a]anthracene & & $80.0-81.6$ & 80.8 \\
benzo[a]pyrene & & - & - \\
benzo[b]fluoranthene & & - & - \\
benzo[k]fluoranthene & & \\
\hline
\end{tabular}


Table 4 Parameters and incremental life cancer risk for people of different age groups and genders in summer and winter.

\begin{tabular}{|c|c|c|c|c|c|c|c|c|c|}
\hline season & age group & gender & $D R$ & $C S F$ & $E F$ & $E D$ & $B W^{\mathrm{a})}$ & $A T$ & $I L C R /\left(\times 10^{-6}\right)$ \\
\hline \multirow[t]{6}{*}{ summer } & \multirow[t]{2}{*}{ young $(<20$ years old $)$} & male & 1.5 & \multirow{6}{*}{10} & \multirow{6}{*}{365} & 15 & 49.4 & \multirow{6}{*}{25550} & 0.3 \\
\hline & & female & 1.0 & & & 15 & 46.2 & & 0.2 \\
\hline & \multirow[t]{2}{*}{ middle-aged (20-64 years old) } & male & 1.9 & & & 40 & 64.1 & & 0.7 \\
\hline & & female & 1.8 & & & 40 & 55.9 & & 0.8 \\
\hline & \multirow[t]{2}{*}{ elderly ( $>64$ years old) } & male & 1.8 & & & 70 & 58.0 & & 1.3 \\
\hline & & female & 1.7 & & & 70 & 49.6 & & 1.4 \\
\hline \multirow[t]{6}{*}{ winter } & \multirow[t]{2}{*}{ young $(<20$ years old $)$} & male & 1.5 & \multirow{6}{*}{10} & \multirow{6}{*}{365} & 15 & 49.4 & \multirow{6}{*}{25550} & 0.3 \\
\hline & & female & 1.6 & & & 15 & 46.2 & & 0.3 \\
\hline & \multirow[t]{2}{*}{ middle-aged ( $20-64$ years old) } & male & 2.5 & & & 40 & 64.1 & & 0.9 \\
\hline & & female & 2.1 & & & 40 & 55.9 & & 0.9 \\
\hline & \multirow[t]{2}{*}{ elderly ( $>64$ years old) } & male & 3.1 & & & 70 & 58.0 & & 2.2 \\
\hline & & female & 3.2 & & & 70 & 49.6 & & 2.6 \\
\hline
\end{tabular}

Notes: a) Data of bodyweight were obtained from China Health Statistics Annuals [42]

consumption habits due to differing seasons and genders were included in this analysis. The parameters used for the calculation were retrieved from our previous studies $[23,41]$ and listed in Table 4.

As shown in Table 4, the risk in winter was higher than that in summer. This was because more water was consumed in during winter, likely as a result of the dry and cold condition in Beijing during this time. The risk to the elderly age group was higher than that to the young and middle-aged groups due to the longer exposure duration and larger volume of water consumed by elderly people. Cancer risks associated with PAHs detected in the source water of Danjiangkou ranged from $10^{-7}$ to $10^{-6}$, which were lower than the accepted value of $10^{-5}$ [43]. The cancer risks associated with PAHs in water from the Danjiangkou reservoir were comparable to those in the Luanhe River [44], and much lower than those in Jiangsu Reach of the Huaihe River [45] and Lanzhou Reach of the Yellow River [46]. Wu et al. reviewed the existing data for PAHs in the source water and drinking water of China and evaluated the health risks [47]. They found that the cancer risks of PAHs in the Danjiangkou reservoir were lower than those in most regions of China. Overall, consuming water from the Danjiangkou reservoir likely poses a low cancer risk.

\section{Conclusions}

In this study, we introduced an adapted version of the CHEMS-1 approach that integrated deconvolution technologies to identify and rank contaminants in the source water of the Danjiangkou reservoir. Reliability of the adapted CHEMS-1 approach was validated. The adapted CHEMS-1 approach was shown to be useful for sitespecific screening of organic contaminants to identify and rank potential priority pollutants. The deconvolution results showed that 46 contaminants from 1093 targets were present in the Danjiangkou reservoir, and 23 contaminants were detected at frequencies higher than $50 \%$. The application of the adapted CHEMS- 1 approach identified 15 contaminants as priorities. Over one half $(53 \%)$ of the top 15 ranked contaminants were PAHs, with chrysene ranked first. The results from the health risk assessment for top-ranked PAHs revealed that cancer risks of the detected PAHs in the source water of Danjiangkou to different populations ranged from $10^{-7}$ to $10^{-6}$, indicating a low cancer risk to consumers.

Acknowledgements This work was supported by the National Natural Science Foundation of China (Grant Nos. 20977102 and 21007077), the Ministry of Water Resources' Special Funds for Scientific Research on Public Causes (No. 201201032) and the Environmental Protection National Commonweal Research Project (No. 200909040).

\section{References}

1. Goss M, Richards C. Development of a risk-based index for source water protection planning, which supports the reduction of pathogens from agricultural activity entering water resources. Journal of Environmental Management, 2008, 87(4): 623-632

2. Qu J, Yin C, Yang M, Liu H. Development and application of innovative technologies for drinking water quality assurance in China. Frontiers of Environmental Science \& Engineering in China, 2007, 1(3): 257-269

3. Gao T, Chen H, Xia S, Zhou Z. Review of water pollution control in China. Frontiers of Environmental Science \& Engineering in China, 2008, 2(2): 142-149

4. Roberson J A. What's next after 40 years of drinking water regulations? Environmental Science \& Technology, 2011, 45(1): 154-160

5. Auer C M, Blunck C, Chow F, Williams D R. Sorting and screening of potential drinking water contaminants: new and existing 
chemicals under the toxic substances control act. In: National Research Council (USA), Identifying Future Drinking Water Contaminants: Based on the 1998 Workshop on Emerging Drinking Water Contaminants. Washington, DC, USA: National Academic Press, 1999, 103-111

6. Ministry of Health of People's Republic of China. Standards for Drinking Water Quality. Beijing: China Standard Press, 2006

7. USEPA. Drinking Water Standards and Health Advisories. Washington, DC, USA: Office of Water, United States Environmental Protection Agency, 2011

8. Federal-Provincial-Territorial Committee on Drinking Water (CDW). Guidelines for Canadian Drinking Water Quality. Ottawa: Health Canada, 2010

9. $\mathrm{Bu} \mathrm{Q}$, Wang $\mathrm{D}$, Wang Z. Review of screening systems for prioritizing chemical substances. Critical Reviews in Environmental Science and Technology, 2013, 43(10): 1011-1041

10. USEPA. Fact Sheet: Final Third Drinking Water Contaminant Candidate List (CCL 3). Washington, DC, USA: Office of Water, United States Environmental Protection Agency, 2009

11. Bowes M, Brown M, Rivas Y, Butler D, Zeiger E. Introduction and executie summary. In: Office of Technology Assessment, Screening and Testing Chemicals in Commerce. Washington, DC, USA: U.S. Office of Technology Assessment, 1995, 1-3

12. Li L, Shi Z H, Yin W, Zhu D, Ng S L, Cai C F, Lei A L. A fuzzy analytic hierarchy process (FAHP) approach to eco-environmental vulnerability assessment for the Danjiangkou reservoir area, China. Ecological Modelling, 2009, 220(23): 3439-3447

13. Zhang J, Meng F, Lu Y, Jing Y, Zhang H, Zhang B, Zhang C. Ecological assessment of lakeshore wetland rehabilitation on eastern route of South-to-North Water Transfer Project. Frontiers of Environmental Science \& Engineering in China, 2008, 2(3): 306310

14. Wang C, Wang Y Y, Wang P F. Water quality modeling and pollution control for the Eastern route of South to North water transfer project in China. Journal of Hydrodynamics, Series B, 2006, 18(3): 253-261

15. Davis G A, Kincaid L E, Swanson M B, Schultz T W, Bartmess J E, Griffith B, Jones S L. Chemical Hazard Evaluation for Management Strategies: A Method for Ranking and Scoring Chemicals by Potential Human Health and Environmental Impacts. Washington, DC, USA: Office of Research and Development, United States Environmental Protection Agency, 1994

16. Swanson M B, Davis G A, Kincaid L E, Schultz T W, Bartmess J E, Jones S L, George E L. A screening method for ranking and scoring chemicals by potential human health and environmental impacts. Environmental Toxicology and Chemistry, 1997, 16(2): 372-383

17. Wylie P L. Screening for 926 Pesticides and Endocrine Disruptors by GC/MS with Deconvolution Reporting Software and a New Pesticide Library. Santa Clara, California USA: Agilent Technologies, Inc., 2006

18. Gómez M J, Gómez-Ramos M M, Agüera A, Mezcua M, Herrera S, Fernández-Alba A R. A new gas chromatography/mass spectrometry method for the simultaneous analysis of target and non-target organic contaminants in waters. Journal of Chromatography A, 2009, 1216(18): 4071-4082

19. Quimby B, Szelewski M. Screening for Hazardous Chemicals in
Homeland Security and Environmental Samples Using a GC/MS/ ECD/FPD with a 731 Compound DRS Database. Santa Clara, California, USA: Agilent Technologies, Inc., 2006

20. Zhong W, Wang D, Xu X, Luo Q, Wang B, Shan X, Wang Z. Screening level ecological risk assessment for phenols in surface water of the Taihu Lake. Chemosphere, 2010, 80(9): 998-1005

21. Senese V, Boriani E, Baderna D, Mariani A, Lodi M, Finizio A, Testa S, Benfenati E. Assessing the environmental risks associated with contaminated sites: definition of an Ecotoxicological Classification index for landfill areas (ECRIS). Chemosphere, 2010, 80(1): 60-66

22. Snyder E M, Snyder S A, Giesy J P, Blonde S A, Hurlburt G K, Summer C L, Mitchell R R, Bush D M. SCRAM: a scoring and ranking system for persistent, bioaccumulative, and toxic substances for the north american great lakes: Part I: Structure of the scoring and ranking system. Environmental Science and Pollution Research, 2000, 7(1): 51-61

23. Xu P, Huang S, Wang Z, Lagos G. Water consumption habit in general population of Shanghai and Beijing, China. Asian Journal of Ecotoxicology, 2008, 3(3): 224-230 (in Chinese)

24. Yang Y, Zhang X X, Korenaga T. Distribution of polynuclear aromatic hydrocarbons (PAHs) in the soil of Tokushima, Japan. Water, Air, and Soil Pollution, 2002, 138(1): 51-60

25. Yunker M B, Macdonald R W, Vingarzan R, Mitchell R H, Goyette D, Sylvestre S. PAHs in the Fraser River basin: a critical appraisal of PAH ratios as indicators of PAH source and composition. Organic Geochemistry, 2002, 33(4): 489-515

26. Peng B, Huang Z, Wang C. On probing trace organic pollutants in Danjiangkou reservoir. Yangtze River, 1997, 28(1): 27-29 (in Chinese)

27. Zhou T J, Tai C, Zhao T Q, Wu L, Wang Q Q. Water environmental health risk assessment of PAHs in Haoping river in Danjiangkou reservoir area. Journal of Henan Polytechnic University (Natural Science), 2009, 28(6): 801-806 (in Chinese)

28. Bielicka-Daszkiewicz K, Dębicka M, Voelkel A. Comparison of three derivatization ways in the separation of phenol and hydroquinone from water samples. Journal of Chromatography A, 2004, 1052(1-2): 233-236

29. Budavari S. The Merck Index: An Encyclopedia of Chemicals, Drugs, and Biologicals. Whitehouse Station, Hunterdon County, New Jersey, USA: Merck, 1996

30. Veldhoen N, Skirrow R C, Osachoff H, Wigmore H, Clapson D J, Gunderson M P, van Aggelen G, Helbing C C. The bactericidal agent triclosan modulates thyroid hormone-associated gene expression and disrupts postembryonic anuran development. Aquatic Toxicology, 2006, 80(3): 217-227

31. Zorrilla L M, Gibson E K, Jeffay S C, Crofton K M, Setzer W R, Cooper R L, Stoker T E. The effects of triclosan on puberty and thyroid hormones in male Wistar rats. Toxicological Sciences, 2009, 107(1): 56-64

32. Rule K L, Ebbett V R, Vikesland P J. Formation of chloroform and chlorinated organics by free-chlorine-mediated oxidation of triclosan. Environmental Science \& Technology, 2005, 39(9): 3176-3185

33. Suzuki T, Yaguchi K, Suga T, Nakagawa Y. Cytotoxic effects of 2,6-di-tert-butyl-4-methylphenyl N-methylcarbamate (terbutol) herbicide on hepatocytes and mitochondria isolated from male rats. 
Environmental Toxicology and Pharmacology, 1997, 3(3): 167-173

34. Mizukami Y. Frontier density pattern of dibenzofurans: a relation between structures and toxicity. Journal of Molecular Structure (Theochem), 2004, 672(1-3): 161-164

35. Groshart C, Okkerman P C. Towards the Establishment of a Priority List of Substances for Further Evaluation of their Role in Endocrine Disrupters. Delft: BHK Consulting Engineers, 2000

36. Song A. Survey and countermeasure pollution sources in the upper and middle reaches of Danjiang river. Journal of Northwest Hydroelectric Power, 2004, 20(1): 74-75 (in Chinese)

37. Zhao W Y, Hu J Q. Present status analysis to non-point source pollution in Danjiangkou reservoir. South-to-North Water Transfers and Water Science \& Technology, 2007, 5(2): 50-52 (in Chinese)

38. Xu Z, Xu T, Pu Q. Protection and management of water resources of Danjiangkou reservoir area and its upstream basin. Yangtze River, 2011, 42(2): 16-20 (in Chinese)

39. Nisbet I C T, LaGoy P K. Toxic equivalency factors (TEFs) for polycyclic aromatic hydrocarbons (PAHs). Regulatory Toxicology and Pharmacology, 1992, 16(3): 290-300

40. USEPA. The Risk Assessment Guidelines of 1986. Washington, DC, USA: Office of Emergency and Remedial Response, United States Environmental Protection Agency, 1986

41. Bu Q, Wang D, Wang Z, Gu J, Cao N. Removal analysis on polycyclic aromatic hydrocarbons and halogenated alkanes by water processing. Water \& Wastewater Engineering, 2011, 37(11): 9-15 (in Chinese)

42. Ministry of Health of People's Republic of China. China Health Statistics Annuals. Beijing: People's Medical Publishing House, 2007

43. Aylward L L, Kirman C R, Blount B C, Hays S M. Chemicalspecific screening criteria for interpretation of biomonitoring data for volatile organic compounds (VOCs) - application of steadystate PBPK model solutions. Regulatory Toxicology and Pharmacology, 2010, 58(1): 33-44

44. Li Y, Liu J, Cao Z, Lin C, Yang Z. Spatial distribution and health risk of heavy metals and polycyclic aromatic hydrocarbons (PAHs) in the water of the Luanhe River Basin, China. Environmental Monitoring and Assessment, 2010, 163(1-4): 1-13

45. Wang B, Yu G, Yu Y J, Huang J, Hu H Y, Wang L S. Health risk assessment of organic pollutants in Jiangsu reach of the Huaihe River, China. Water Science and Technology, 2009, 59(5): 907916

46. Dong J, Wang S, Shang K. Water environment health risk assessment of polycyclic aromatic hydrocarbons in the Lanzhou Reach of the Yellow River. Journal of Agro-Environment Science, 2009, 28(9): 1892-1897 (in Chinese)

47. Wu B, Zhang Y, Zhang X X, Cheng S P. Health risk assessment of polycyclic aromatic hydrocarbons in the source water and drinking water of China: quantitative analysis based on published monitoring data. Science of the Total Environment, 2011, 410-411: 112-118 